\title{
Substance/Drug Abuse Among Nigerian Youths: The Roles of Curriculum Reform
}

\author{
DR JOHN EGHAREVBA DR ELIZABETH O. EGHAREVBA \\ Department of Curriculum and Instructional Technology, Faculty of Education, University of Benin.
}

\begin{abstract}
Substance abuse is a serious global and international issue particularly in developing countries like Nigeria where the problem of drug abuse has become a major concern both to the government and to the society. This paper examined the meaning of drugs and substances that are commonly abused such as stimulants, narcotics among others. The paper also examined some of the risk factors involved such as smuggling substances of abuse through porous seaports and land borders as a result of corruption and compromises at the point of entries. The prevalence of drug abuse, effect of drug abuse and the importance of drug/substance abuse education were also highlighted. The various stakeholders in drug education and the need for curriculum reforms and development were also identified.
\end{abstract}

Keywords: Curriculum reform, drug education, drug abuse.

DOI: $10.7176 / \mathrm{JEP} / 12-29-04$

Publication date:October $31^{\text {st }} 2021$

\section{INTRODUCTION}

Substance abuse is a serious global and international issue particularly in developing countries like Nigeria where the problem of drug abuse among youths has been a scourge to the overall sustainable development of the nation (Okafor, 2020). The term 'drug' refers to "any substance, which when taken into a living organism, limits ill-health", however if drugs are abused, they can become very "destructive to the individual and to society at large" (Nnachi, 2007). Odejide (2000) posited that drug is said to be abused when its use is not pharmacologically necessary especially when used in the face of legal prohibition or when a socially acceptable beverage is used excessively. Drug abuse is one of the health-related problems among Nigerian youths and has been a source of concern to educational stakeholders. Its social implications to undergraduate students cannot be quantified (Okafor, 2020). Since the problem of drug abuse is prevalent among youths who in most cases are ignorant of the dangers inherent in drug addiction (Adenaike A.S., Surakat A.M., Adegboyega S.B., \& Senuga M.A. 2014),there is need for a standard form of drug abuse curriculum to be added to the school curriculum (Oliha, 2014). Effective drug education becomes important as young people are faced with many influences to use both licit and illicit drugs. Proper education when given, can play a counterbalancing role in shaping a normative culture of safety, moderation, and informed decision making (Victoria State Government, 2020).

The consequences of substance use are diverse, including acute and chronic health, social as well as psychological problems. There is disruption of interpersonal relationships particularly within the family, marginalization, criminal behaviour, school failure, vocational problems and failure to achieve normal adolescent milestones (Oliha, 2014).The study by Adenaike et al in 2014 revealed that a significance relationship existed between drug abuse in youths and their academic performance (failure) with about $93.56 \%$ of respondents affirming the assertion. The study therefore concluded that a real and definite relationship exists between drug abuse and academic performance in Nigeria.

The alarming evidence in the prevalence and consequences of substance abuse among students calls for concern and challenge to all helping professions to mount strategies of equipping youths with skills of living devoid of substance abuse (Oliha, 2014). It is important to involve relevant stakeholders in developing, designing, and conducting evaluations of substance use disorder prevention programs and treatment (Rural Health, 2020). Adequate and prompt sensitisation education about the consequences of drug abuse combined with effective counselling programme to prevent/ameliorate the problem is important (Adenaike et al, 2014). This can be achieved through curriculum reform and drug education in addition to the involvement of other relevant stakeholders.

\section{Drug: definition}

A drug refers to a substance that could bring about a change in the biological function through its chemical actions (Okoye, 2001). Drugs, are substances which, when taken, can limit cognition, perception, mood, behaviour and overall body function. It can also produce a change in biological functions through its chemical actions (Balogun, 2006). According to the Federal Drug Agency (FDA), drugs are defined as articles intended for use in the diagnosis, cure, mitigation, treatment, or prevention of disease and as articles (other than food) intended to affect the structure or any function of the body of man or animals (FDA, 2017). Therefore, almost any ingested or topical or injectable product that, through its label or labeling (including internet websites, 
promotional pamphlets, and other marketing material), is claimed to be beneficial for such uses is regarded as a drug. This definition also includes components of drugs, such as active pharmaceutical ingredients (FDA, 2018).

\section{Classes of Drugs /Substances commonly abused}

According to Oshodin (2014), drugs such as cough syrup, codeine, analgesics, alcohol are commonly abused. The National Agency for Food and Drug Administration and Control also stated that stimulants, hallucinogens, sedatives, tranquilizers etc are used and misused in Nigeria (NAFDAC, 2000). Drugs can be classified under the following groups:

a. Stimulants: These are substances that act and stimulate the central nervous system directly.

The users of these substances at the initial stage experience pleasant effects such as energy increases. The major source of these comes from caffeine substances.

b. Hallucinogens: These are drugs that alter the sensory processing unit in the brain. They produce distorted perception, feelings of anxiety and euphoria, sadness and inner joy. They normally come from marijuana, LSD, etc.

c. Narcotics: These drugs relieve pain, induce sleep and are addictive. They are found in heroin, codeine, opium, etc.

d. Sedatives: These drugs are among the most widely used and abused because of the belief that they relieve stress and anxiety. Some of them induce sleep, ease tension, cause relaxation or help users to forget their problems. These include: valium (diazepam), alcohol, promethazine, and chloroform.

e. Tranquilizers: Tranquilizers are believed to produce calmness without bringing drowsiness. They are chiefly derived from Librium, Valium among others.

f. Miscellaneous: This is a group of volatile solvents or inhalants that provide euphoria, emotional disinhibiting and ever-lasting distortion of thought to the user. The main sources are glues, spot removers, tube repair, perfumes, chemicals, etc.

A study by Dumbili (2015) revealed that heavy episodic alcohol drinking is also growing among adolescents in Nigeria and there are no written alcohol control policies to regulate the production and availability of alcohol.

Factors Responsible for the Prevalence of Drug/Substance Abuse

As opined by the Director General of NAFDAC, the abuse of drugs in Nigeria is caused by many factors including love for money by peddlers, disobedience to the laws of the country, proliferation of the market with individuals who sell medicines, lack of control of prescription in the healthcare facilities and lack of control of dispensing among dispensers. Other reasons for abuse of drugs include the ease of smuggling substances or drugs through the porous seaports and land borders, corruption and compromises at the point of entries, diversion of legitimate exports to illicit use, weakness in inspections and weak penalties for sellers and traffickers (Adeyeye, 2018).

Social factors that have resulted in the abuse of drugs include decline of family value systems, parents not playing their roles properly, children and youth therefore not receiving proper guidance, peer pressure, social media influence, poverty and unemployment (Adeyeye, 2018). As opined by Aderinto (2002), predisposing factors of illicit drug use in Nigeria are joblessness, peer pressure, search for identity, emotional and psychological stresses among several others. A study carried out by Boys Marsden \& Strang (2001) identified several reasons for drug use amongst young people, these included drugs for relaxation (96.7\%), intoxication $(96.4 \%)$, to keep awake at night while socializing $(95.9 \%)$, activity enhancement $(88.5 \%)$ and alleviation from depression $(86.8 \%)$.

The motives for using alcohol include staying awake in order to study at night, drinking to forget one's problems, drinking to alleviate anxiety and drinking to enjoy festivals. Peer pressure in the form of drinking to satisfy friends or not to be seen as different from one's group was also highlighted as a reason for alcohol use (Dumbili, 2015).

\section{Prevalence of Drug Abuse/Substance Abuse}

In 2018, a survey conducted in Nigeria revealed that the prevalence rate of any drug use in Nigeria was estimated at 14.4 per cent or 14.3 million people aged between 15 and 64 years. The extent of drug use in Nigeria is comparatively higher compared with the 2016 global annual prevalence of any drug use 5.6 per cent among adult population (UNODC, World Drug Report, 2018). In June 2021 however, the United Nations Office on Drugs and Crime (UNODC) reported that around 275 million people used drugs worldwide in 2020, while over 36 million people suffered from drug use disorders. According to the latest global estimates, about 5.5 per cent of the population aged between 15 and 64 years have used drugs at least once in the past year, while 36.3 million people, or 13 per cent of the total number of persons who use drugs, suffer from drug use disorders. In Nigeria, with $14.4 \%$ the drug use prevalence is significantly higher than the global average. (UNODC, World 
Drug Report, 2021). The 2018 report revealed that drug use was most common among those who were between the ages of 25 and 39 years, while the rates of past year use were lowest among those who were below 24 years of age. Among every 4 drug users in Nigeria 1 is a woman. More men (annual prevalence of 21.8 per cent or 10.8 million men) than women (annual prevalence of 7.0 per cent or 3.4 million women) reported past-year drug use in Nigeria (UNODC, World Drug Report, 2018).

Cannabis was the most commonly used drug followed by opioids, mainly the non-medical use of prescription opioids (mainly tramadol, and to lesser extent codeine, or morphine) and cough syrup (containing codeine or dextromethorphan) (UNODC, World Drug Report, 2018). Tramadol is a synthetic opioid analgesic used to treat moderate to severe pain and is the most abused medicine among addicts. Previously, codeine could be obtained as an over-the-counter painkiller and cough medicines in Nigeria but consumers often become addicted. The risk of addiction is great, and in many countries including Nigeria, consumers are presently required to have prescriptions for all opioid-based medications (Adeyeye, 2018). The non-medical use of tranquilizers $(0.5$ per cent $)$, and the use of ecstasy ( 0.3 per cent $)$, inhalants $(0.3$ per cent $)$ amphetamines $(0.2$ per cent) and cocaine ( 0.1 per cent) though not insignificant remains lower than the drugs mentioned earlier (UNODC, World Drug Report, 2018).

A study which described the patterns and determinants of alcohol use among Nigerian adolescents in secondary school revealed more current and lifetime alcohol use among males than females (Dumbili EW, 2015). Adeyemo et al 2016 reported that $46.6 \%$ of the sample respondents have taken drugs for non-medical purposes at least once alcohol and coffee being the most commonly abused drugs. Controlled prescription drugs (including Valium and Ritalin) were reported to be among the fourth most abused substances in America behind only marijuana, alcohol and tobacco (Lennox RD, Cecchini MA, 2008).

\section{Effects of Drug Abuse/Substance Abuse on the Youths}

Drug abuse is a major public health, social and individual problem. It has become a global concern and in Nigeria because of its effect on the youth and the nation as a whole. While youths are supposed to be the major agent of change and development, some of them have been destroyed by drug abuse (rendering them unproductive). It has a negative impact on the education of undergraduates in different universities across the globe (Okafor, 2020). Muritala, Godwin, Anyio, Muhammad, Ajiboye (2015) opined that illicit drug use is harmful to students' academic performance. They reported that there was a significant difference between the academic performance of students who abuse drugs and those who do not. They also stated that alcohol and drug consumption may have some detrimental effects on pupils' cognitive abilities, for instance, by decreasing their ability to concentrate. Drug and alcohol consumption undermine students' progress by making them less likely to attend classes or keep up with their studies. In their research on the effect of drug abuse on educational performance of some adolescent drug abusers in Ibadan, Fayombo and Aremu (2000) found that the misuse of marijuana has reached an epidemic level in the present Nigeria society and the drug abuse could lead to poor academic achievement or even halt one's entire academic process.

Other effects of drug abuse include physical withdrawal symptoms and compulsive behavior such as is present in tramadol abuse. Although tramadol has no effects on the respiratory system, overdose causes arrhythmias, cramps, coma and death. The misuse of codeine products contributes to severe health outcomes including liver damage, stomach ulceration, respiratory depression, coma and death (Adeyeye, 2018).

The impact of substance abuse on the family and individual family members merits attention. The family remains the primary source of attachment, nurturing, and socialization for humans in our current society. Drug abuse negatively affects the emotional and behavioral patterns from the inception of the family, resulting in poor outcomes for the children and adults in the family (Lander, Howsaren, Byrne,2013).

\section{Drug/substance abuse Education}

Drug/substance abuse Education includes factual data about what substance abuse is, warning signs of addiction, information about how specific drugs affect the mind and body, the consequences of addiction on one's physical and mental health, family relationships and other aspects of functioning and how and why substances are abused (Miller, 2020).The goal is to educate students about the physical, psychological and social dangers of drug and alcohol use and abuse (Freeman, 2017). "Lower perception of drug use risks has been linked to higher rates of drug use, and the findings of UNODC's 2021 World Drug Report highlight the need to close the gap between perception and reality to educate young people and safeguard public health," (UNODC, World Drug Report, 2021). Considering the negative effects of drug/substance abuse on youths and the society at large, the importance of drug abuse education therefore, cannot be overemphasized. Education about substance abuse is an important part of helping individuals understand the many aspects of the topic. When students are provided with current and fact-based information about alcohol and other drug use, they are capable of navigating situations where substance use is prevalent and making decisions that reduce harmful consequences for themselves and their peers. Through peer-to-peer education and outreach, comprehensive programming, and by providing 
support and access to resources, the program empowers students to make safer decisions that will enhance their academic and personal success (University of Maryland, 2020). Substance abuse education is important for children, teenagers, and adults alike, as there are many misconceptions about commonly used legal and illegal substances, such as alcohol and marijuana. Ensuring that children are educated about drugs can help prevent them from using them, especially ones that are made to sound harmless, but are in reality very addictive or dangerous to the body (Miller, 2020). Lennox and Cecchin (2008) evaluated the capacity of a drug education program to produce a long-term impact on students' drug use behaviors in a student-setting. After controlling for pretest levels of use, at six months after receiving the drug prevention curriculum students in the drug education group had lower levels of current drug use than students in the comparison group. Significant reductions were observed for alcohol, tobacco, and marijuana - important categories of drug abuse for this population - as well as certain categories of "hard drugs" including controlled prescription drugs, cocaine, and ecstasy. The study also reported changes in knowledge, attitudes and perception of risk (Lennox \& Cecchini, 2008).

\section{Role of Curriculum in Drug Education}

A curriculum is the combination of instructional practices, learning experiences, and students' performance assessment that are designed to bring out and evaluate the target learning outcomes of a particular course. It is a standards-based sequence of planned experiences where students practice and achieve proficiency in content and applied learning skills and is a central guide for all educators as to what is essential for teaching and learnin. (Rhode Island Department of education, 2021). Integrating drug abuse education into the school curriculum would go a long way in curbing the menace of drug abuse. Akanbi (2015) recommended that campaigns against substance use should be incorporated in health education curricula of colleges of education with special focus on the adverse consequences of the substances used and establishment of counselling centres for drug control. The same should apply to secondary and other tertiary institutions.

\section{Role of Stakeholders in Drug Education}

Preventing and reducing drug use among in-school youth demands a comprehensive intervention that relies on the efforts of multiple stakeholders (Gaynor, Quartz, Houle, Carr, Romero, 1993). Schools alone cannot provide programs with the time, staff, and resources necessary to meet the needs of all students. The programs, for example, also must rely on services and contributions from local law enforcement agencies, public health agencies, community-based organizations, volunteers, and parents (Gaynor et al 1993). Schools, working in collaboration with community partners and health care professionals, are well situated to identify students with signs and symptoms of illicit drug abuse. Poor school performance, underachievement, and truancy may be manifestations of substance use and indicate the need for evaluation and referral of these students to physicians (Flay 2000;Cuijpers 2002; Murray, Belenko, 2005).

In Nigeria, the Federal Government (FG) through its agencies (such as the Ministry of Education and the National Universities Commission) is an important stakeholder in curriculum reforms and development in drug education. The FG can achieve reduction in the number of individuals that would indulge in drug abuse by including drug education as part of the school curriculum, starting from primary education through university education.

\section{Conclusion}

The increasing prevalence of substance/drug abuse among youths especially in Nigeria, is a major issue that demands real attention. Findings from studies on drug abuse in different nations of the world have shown that the burden of drug abuse is still high despite the existing drug laws, policies, and strategies for prevention. According to the UNODC World Drug Report in 2021, the number of people using drugs increased by 22 per cent between the years 2010-2019. To a large degree, baseline survey responses were similar to drug use patterns seen in large national surveys.

It is an established fact that drug abuse has destroyed many lives and led to untimely death. In other to reverse this trend, there is need for attitudinal change through drug education. Measures to reduce the burden should involve the community, schools, government, and non-governmental organizations. Preventive measures should target the youths and the students by including drug education in the school curriculum. Proper orientation and commitment towards including drug education in the school curriculum and the effective teaching and learning of drug education in our schools will not only improve conceptualization of values for drug education, but will also curtail societal ills such as drug abuse, cultism, political thuggery, electoral violence, armed robbery, domestic violence and negative health implications including psychiatric illness.

This paper tried to address the issue of drug abuse and suggested that integrating drug abuse education into the school curriculum would go a long way in curbing the menace of drug abuse both in Nigeria and internationally. 


\section{Recommendations}

Government should enact stringent law that will curtail the illegal use of drugs.

Government should provide rehabilitation centers for drug abuse related cases.

Drug education should be included in the school curriculum and also taught to all students, at all levels of education.

There should be enlightenment programmes through the media on the danger associated with drug abuse in the society. Bill boards should be provided in strategic locations on the danger of drug abuse.

Curriculum planners such as the Nigerian Educational Research and Development Council are also important as they develop curriculums that will accommodate the content of drug education in the school curriculum.

Curriculum implementers including teachers of both primary and secondary schools and lecturers in higher institutions are also important stakeholders in drug education.

The mass media/social media plays a vital role in public enlightenment on the danger of drug abuse.

The family is also a major instrument to containing drug abuse among adolescents through constant monitoring of the children/wards, appropriate discipline and family based counseling/interventions.

Religious organizations through preaching against drug abuse in the worship centers also assist to reduce the menace of drug abuse.

\section{Acknowledgements}

\section{REFERENCES}

Adenaike, A. S., Surakat A. M., Adegboyega S. B., \& Senuga M. A. (2014). Menace of Drug Abuse on Youth Development and Academic Performance: Evidence from Nigeria. Journal of social and Behavioural Sciences, 3(2), 1.

Aderinto AA (2002). The concept of social problem. In U.C. Isiugo-Abanihe, A.N. Isamah \& J.O. Adesina. (Eds.) Currents and perspectives in sociology (pp 335 - 348)Ikeja: Malthouse Press Limited.

Adeyemo, F.O., Ohaeri, B., Okpala, P.U., Ogodo, O. (2016). Prevalence of drug abuse amongst university students in Benin City, Nigeria, Public Health Research. 31-37 6(2), 31-37.

Adeyeye MC (2018). The problem of drugs/substance abuse in Nigeria: A symposium by Professor Mojisola Christianah Adeyeye, Director General, National Agency for Food and Drug Administration and Control (NAFDAC)at the University of Benin, Benin City. Available online at: https://www.nafdac.gov.ng/theproblem-of-drugs-substance-abuse-in-nigeria-a-symposium-by-professor-mojisola-christianah-adeyeyedirector-general-nafdac-at-the-university-of-benin-benin-city/. Accessed 6th May 2020

Balogun, S.K. (2006). "Chronic intake of separate and combined alcohol and nicotine. Center for Disease Control (CDC, 2000). HIV/AIDS: Frequently asked questions on HIV/AIDS. Retrieved from www.cdenpin.org/hiv/faq/preventionJitm

Boys, A., Marsden, I.\&Strang, J., (2001). Understanding reasons for drug use amongst young people: A functional perspective. Health Education Research, 16, 4, 457-469.

Cuijpers P (2002). Effective ingredients of school-based drug prevention programs: A systematic review. Addict Behaviour. 27, 1009- 1023.

Dumbili E.W., (2015). A review of substance use among secondary school students in Nigeria: Implications for policies in drugs education prevention \& policy, 22(5), 387-399.

Fayombo, G. A., Aremu S. (2000). Drug education and its effects on the educational performance of some adolescents drug abusers in Ibadan. The Counsellor, drug abusers in Ibadan The Counsellor, 18 (5), 378 387.

Federal Drug Agency (2017). Definition of a drug. Available online at: https://www.fda.gov/drugs/informationhealthcare-professionals-drugs/transcript-definition-drug-april-2017. Accessed 6th May 2020

Federal Drug Agency (2018). Human drugs. Available online at: https://www.fda.gov/industry/regulatedproducts/human-drugs. Accessed 6th May 2020

Flay BR (2000). Approaches to substance use prevention utilizing school curriculum plus social environment change. Addict Behaviour. $25: 861-88$.

Freeman, E. (2017). Drug education and prevention programs in elementary schools. Available online at: https://classroom.synonym.com/drug-education-prevention-programs-elementary-schools-9606.html. Accessed 8th May 2020.

Gaynor, JR., Quartz, KH., Houle, D.M., Carr, C.R., Romero, F.S, (1993). Recognizing the role of stakeholders in drug, alcohol, and tobacco prevention and reduction programs. Paper presented at the Annual Meeting of the American Educational Research Association (Atlanta, GA, April 12-16, 1993. Available online at: https://files.eric.ed.gov/fulltext/ED362974.pdf. Accessed $8^{\text {th }}$ May 2020.

Lander, L., Howsaren, J., Byrne, M. (2013). The impact of substance use disorders on families and children: From theory to practice. Soc Work Public Health, 28(3-4), 194-205. doi: 10.1080/19371918.2013.759005. 
Lennox, R.D, \& Cecchini, M.A., (2008). The $N A R C O N O N^{\mathrm{TM}}$ drug education curriculum for high school students: A non-randomized, controlled prevention trial. Subst Abuse Treat Prev Policy3,8.

Miller, L., (2020). Drug Education Resources. Available online at: https://www.projectknow.com/drugaddiction/resources/. Accessed $8^{\text {th }}$ May 2020.

Muritala, I.A., Godwin, A., Anyio, B.T., Muhammad, M., Ajiboye, S.A., (2015). Impact of substance abuse on academic performance among adolescent students of colleges of education in Kwara State, Nigeria. Journal of Education and Practice,6(28):108.

Murray, L.F., Belenko S (2005). CASASTART: A community-based school-centered intervention for high-risk youth. Subst Use Misuse. 40 :913-933.

NAFDAC (2008). Do drugs control your life? Know the risks. Abuja: NAFDAC.

Nnachi, R. O. (2007). Advanced psychology of learning and scientific enquiries, Enugu: J.J. Classic Publishers Ltd.

Odejide, A. O. (2000) Research, prevention and treatment of alcohol and drug abuse in Nigeria Probem and Prospects. Paper presented at the 10th Anniversary Lecture of CRISA JOS

Okafor, I.P. (2020). Causes and consequences of drug abuse among youth in Kwara State, Nigeria. Canadian Journal of Family and Youth, 12(1), 147-162.

Okoye, N. N., (2001). The adolescents and hard drugs: A psychological concern in R.U.N, Okonkwo \& R. O. Okoye (Eds.). The Nigerian Adolescent in Perspective. A Publication of the Nigerian Society for Education.

Oliha, J.A. (2014). Adolescent and drug abuse in tertiary institution. Implication for Counselling. British Journal of Education. 2(1),1-9.

Oshodin, O. G. (2004). Are you not also guilty of drug abuse: Health education and cultural strategies to the rescue, Inaugural Lecture Series 72 Benin: University of Benin press.

Rhode Island Department of Education (2021). Curriculum Definition. Available online at https://www.ride.ri.gov/InstructionAssessment/Curriculum/CurriculumDefinition.aspx. Accessed 31st August 2021.

Rural Health Information Hub (2020). Stakeholders involved in the evaluation of substance use. Available online at: https://www.ruralhealthinfo.org/toolkits/substance-abuse/5/stakeholder-involvement. Accessed 6th May 2020.

United Nations Office on Drugs and Crime (2018). Drug use in Nigeria. world drug report, 2018. Available online at: https://www.unodc.org/documents/data-andanalysis/statistics/Drugs/Drug_Use_Survey_Nigeria_2019_BOOK.pdf. Accessed 8th May 2020

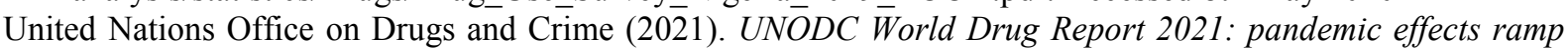
up drug risks, as youth underestimate cannabis dangers. Available online at: https://www.unodc.org/nigeria/en/unodc-world-drug-report-2021_-pandemic-effects-ramp-up-drug-risks-as-youth-underestimate-cannabis-dangers.html Accessed 2nd October 2021.

University of Maryland Health Centre (2020). Alcohol and other drug education. Available online at: https://health.umd.edu/wellness-advocacy/alcohol-other-drug-education. Accessed 8th May 2020.

Victoria State Government (2020). Education and Training: Drug Education. Available online at:https://www.education.vic.gov.au/school/teachers/teachingresources/discipline/physed/Pages/drugeducati on.aspx. Accessed 1st May 2020. 